\title{
Amended decision by gynecology board good for male patients and cancer research
}

$\mathrm{A}$ recent decision by the American Board of Obstetrics and Gynecology that largely limited gynecologists to caring only for women rankled doctors trying to prevent and treat anal cancer in men.

The decision barring US gynecologists from treating men - outside of limited situations, such as addressing fertility issues or sexually transmitted infections in male partners of female patients - was later amended after doctors protested in the media and in letters to the board. The amendment allows gynecologists to evaluate and treat sexually transmitted infections in men, and permits gynecologists to perform anoscopies on men to look for abnormal growths in the anal canal.

According to the board's spokesman, David Margulies, the definition of a board-certified gynecologist was widened after the board realized that several gynecologists had been asked to participate in a randomized controlled trial to determine if treating anal dysplasia, a precancerous condition, reduces cancer incidence in men and women.

Margulies said the initial, more-stringent definition was intended to stop gynecologists from "going into ancillary practices such as plastic surgery or liposuction" for women and men. But a letter from the board to Dr. Elizabeth Stier, an obstetrician-gynecologist at Boston Medical Center in Massachusetts, indicated that the decision had been made to preserve gynecology as a female-centred specialty.

"There are currently too few doctors to provide care for pregnant women, too few to manage female cancer and too few to provide necessary preventive women's health care. We need to maintain and even increase the number of physicians devoted to women's health," stated the letter, in response to a complaint from Stier.

The letter also noted that there were plenty of other physicians who could

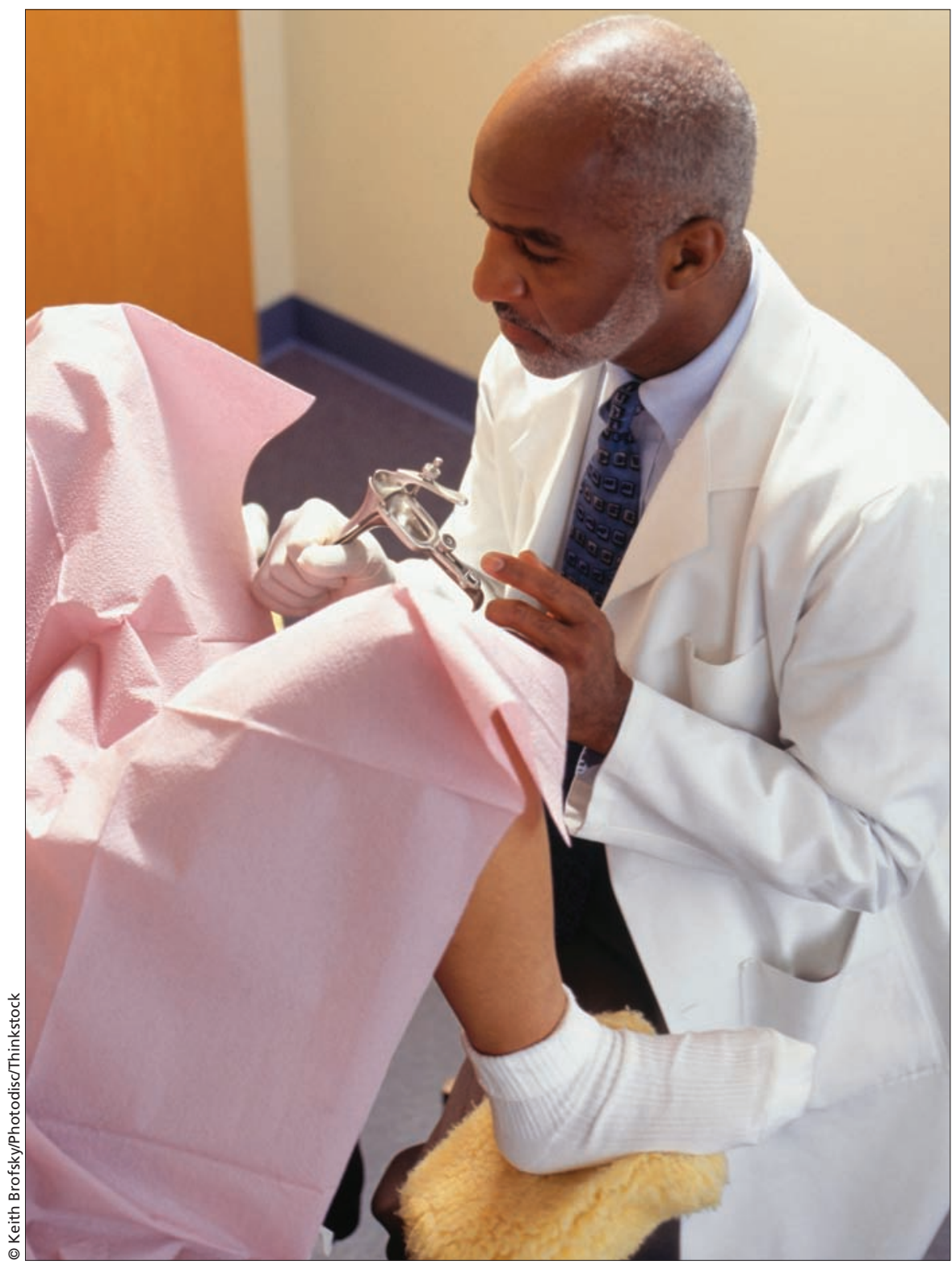

Though the majority of their patients are women, gynecologists also screen and treat male patients for conditions such as anal cancer.

provide care for men, a notion that Stier disputes. "I think that gynecologists seeing men do so because there is no one else to provide the specified care for the men," she says.

The board's amendment is welcome news to doctors, including Stier, who had enrolled men in a randomized con- trolled trial led by Dr. Joel Palefsky, director of the Anal Neoplasia Clinic, the world's first clinic devoted to anal cancer prevention, at the University of California, San Francisco.

Hoping to convince the medical establishment of the efficacy of anal dysplasia screening for at-risk populations, 
Palefsky is leading a study of about 5000 men and women infected with HIV to see if treating anal dysplasia reduces the rate of anal cancer, which has increased by $2.2 \%$ per year for a decade. He hopes to have results in about eight years.

Anal cancer, like all other HPVrelated cancers, except for cervical cancer, is not routinely screened for, even in at-risk populations. The incidence of anal cancer in HIV-positive men who have sex with men is 131 per 100000 , according to a 2012 study (Clin Infect Dis 2012; 54:1026-34).

"That's twice the highest rate of cervical cancer in any place in the world, including countries without cervical screening," says Palefsky.

Likewise, anal dysplasia is not often looked for or treated, in contrast to cer- vical dysplasia. Routine Pap smears were introduced in the 1950s in the United States and Canada, despite no evidence at the time that treating cervical dysplasia would reduce cervical cancers. Subsequently, the incidence of cervical cancer plummeted by more than 60\% between 1955 and 1992, according to the National Cancer Institute.

In the age of evidence-based medicine, however, "quite rightly, nobody is willing to take our word for it" that doing the same with anal dysplasia would be beneficial, says Palefsky.

In addition to the lack of evidence, part of the reason anal dysplasia is not standardly treated has to do with anatomy, suggested Dr. Robert Yarchoan, director of the Office of HIV and AIDS Malignancy at the National
Cancer Institute, which is funding the study. The anal canal requires more time to heal from treatments — which include liquid nitrogen, laser treatment, electrocautery and surgical excision and is much more prone to complications because of defecation.

"It's harder to treat anal dysplasia as opposed to cervical dysplasia," says Yarchoan.

Another problem is the general discomfort in discussing that part of the body with patients. "There tends to be a fair amount of taboo with anything to do with the anal canal," says Palefsky. "It's not like asking a patient, 'How's your elbow?", — Wendy Glauser, Toronto, Ont.

CMAJ 2014. DOI:10.1503/cmaj.109-4683 